\title{
Deteksi Aritmia pada Elektrokardiogram dengan Metode Jaringan Syaraf Tiruan Kelas Jamak menggunakan Fitur Interval RR, Lebar QRS, dan Gradien Gelombang R
}

\author{
Mar'atus Solikhah, ${ }^{*}$ Nuryani, ${ }^{\dagger}$ dan Darmanto \\ Jurusan Fisika, Fakultas Matematika dan Ilmu Pengetahuan Alam, \\ Universitas Sebelas Maret \\ Jl. Ir. Sutami No.36 A Kentingan, Surakarta 57126
}

\begin{abstract}
Intisari
Penelitian untuk deteksi aritmia pada elektrokardiogram dengan metode Jaringan Syaraf Tiruan (JST) Multilayer Perceptron-Backpropagation (MLP-BP) kelas jamak menggunakan fitur interval RR, interval QRS, serta gradien gelombang $\mathrm{R}$ telah berhasil dilaksanakan. Tipe aritmia yang dideteksi dalam penelitian adalah Premature Ventricular Contraction (PVC), Premature Atrial Contraction (PAC), dan Left Bundle Branch Block (LBBB). Pada penelitian ini dilakukan variasi jumlah fitur sebagai masukan JST, yaitu tiga macam fitur dan dua macam fitur. Hasil penelitian terbaik ditunjukkan pada variasi tiga macam fitur (interval RR, interval QRS, gradien gelombang R ) dengan kinerja berupa sensitivitas, spesifisitas, serta akurasi cukup baik yaitu 94,63\%, $93,94 \%$, serta $94,49 \%$.
\end{abstract}

\begin{abstract}
Research for arrhythmias detection using Multilayer Perceptron-Backpropagation (MLP-BP) Artificial Neural Network (ANN) multiclass method has been successfully implemented. It utilized RR interval, QRS width, and $\mathrm{R}$ wave gradient features. Arrhythmia types used in this study were Premature Ventricular Contraction (PVC), Premature Atrial Contraction (PAC), and Left Bundle Branch Block (LBBB). This study was conducted by varying features number as the input of ANN. The variation includes two and three kinds of features. The best results were found when three features were included. The best performance were $94.63 \%, 93.94 \%$, and $94.49 \%$ in terms of sensitivity, sprcificity and accuracy, respectively.
\end{abstract}

KATA KUNCI: Arrythmia, artificial neural network, electrocardiogram (ECG)

\section{PENDAHULUAN}

Jantung merupakan salah satu organ vital yang berfungsi memompa ke seluruh tubuh manusia. Gangguan fungsi jantung dapat berakibat fatal bagi kesehatan manusia. Beberapa gangguan jantung bahkan dapat menyebabkan kematian.

Penyakit jantung terutama iskemia merupakan penyebab kematian nomor satu di dunia dalam kurun waktu satu dekade dari tahun 2000 hingga 2011 [1]. Data menunjukkan bahwa pada tahun 2011 terdapat sekitar tujuh juta orang meninggal akibat penyakit jantung. Angka ini meningkat dari angka kematian akibat jantung pada tahun 2010 yang berjumlah kurang dari enam juta orang. Bahkan telah diprediksikan pada tahun 2015 terdapat 246 kematian akibat jantung setiap seratus ribu populasi di dunia, dan akan meningkat pada tahun 2030 menjadi 264 kematian [2].

Deteksi penyakit jantung menggunakan elektrokardiografi (EKG) merupakan salah satu cara yang dapat digunakan un-

\footnotetext{
*E-MAIL: s.maratus@gmail.com

$\dagger$ E-MAIL: nuryani@mipa.uns.ac.id
}

tuk mengantisipasi tingginya angka kematian akibat penyakit jantung. EKG adalah suatu alat untuk mendeteksi aktivitas kelistrikan jantung.

Aritmia merupakan salah satu penyakit kelainan terhadap irama jantung. Aritmia adalah suatu kelainan dalam kecepatan, irama, tempat asal dari rangsangan, atau gangguan penghantar yang dapat menyebabkan perubahan dalam urutan normal aktivasi atrium dan ventrikel $[3,4]$. Oleh karena beberapa pasien yang menderita aritmia tidak merasakan gejala apapun, maka perlu adanya otomatisasi deteksi dini untuk aritmia dengan menggunakan EKG.

Tipe aritmia yang difokuskan pada penelitian ini adalah Premature Ventricular Contraction (PVC), Premature Atrial Contraction (PAC) dan Left Bundle Branch Block (LBBB). PVC dan PAC merupakan aritmia yang paling umum terjadi. PVC atau disebut juga dengan kontraksi ventrikel dini adalah denyut dini yang muncul pada sebuah ventrikel jantung [5], Sedangkan PAC atau kontraksi atrium dini adalah denyut dini yang muncul pada atrium jantung. LBBB terjadi ketika serabut berkas kiri menghalangi impuls listrik dari nodus A-V jantung sehingga terjadi keterlambatan depolarisasi ventrikel kiri [6].

Analisis deteksi kelainan jantung yang umum dilakukan 


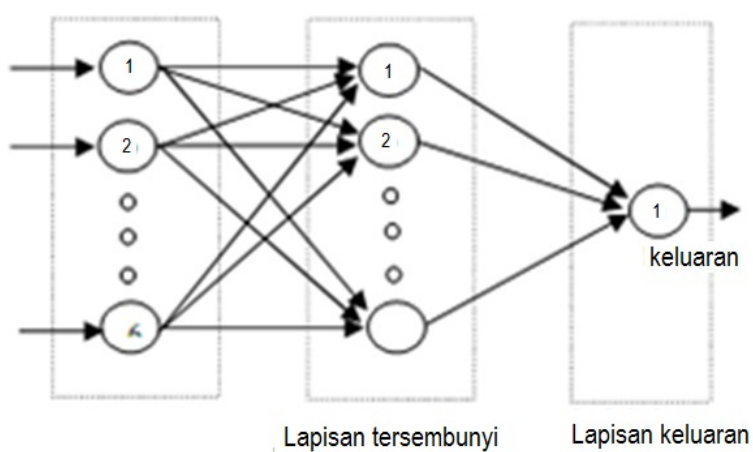

Gambar 1: Sistem backpropagation [14].

dalam dunia kesehatan yaitu dengan melihat grafik rekaman EKG secara manual. Namun teknik ini memerlukan waktu yang cukup lama dan tidak bisa digunakan untuk sistem deteksi dini kelainan jantung. Untuk mengantisipasi hal tersebut maka perlu adanya teknik otomatisasi diagnosis dengan menggunakan metode komputasi.

Salah satu metode yang dapat digunakan untuk klasifikasi gangguan kesehatan adalah metode Jaringan Syaraf Tiruan (JST). JST dibentuk untuk memecahkan suatu masalah tertentu seperti pengenalan pola klasifikasi melalui proses pelatihan atau training [7]. JST bekerja berdasarkan system syaraf seperti otak manusia yang diimplementasikan dalam model matematika untuk pengolahan informasi [8]. Salah satu jenis JST yang biasa digunakan adalah JST Multilayer PerceptronBackpropagation (MLP-BP). JST MLP-BP menggunakan algoritma pembelajaran backpropagation untuk mengubah bobot-bobot yang terhubung dengan neuron-neuron [9]. Gambar 1 menunjukkan desain sistem backpropagation dengan sebuah lapisan tersembunyi.

Berbagai penelitian telah dilakukan untuk otomatisasi deteksi artimia, diantaranya klasifikasi aritmia berupa PVC, LBBB dan RBBB dengan metode pengenalan berbagai macam kategori aritmia berdasarkan karakteristik ekstraksi fitur dari sinyal EKG [10]. Selain itu, telah dilakukan pula penelitian mengenai sistem klasifikasi kelainan jantung berdasarkan citra digital electrocardiogram menggunakan JST Learning Vector Quantization (LVQ) [11]. Kondisi yang dideteksi pada penelitian ini antara lain jantung dengan kelainan bradikardi, aritmia, takikardi, serta kondisi jantung normal.

Dekomposisi wavelate dengan adaptive treshold telah digunakan untuk klasifikasi aritmia akibat kelainan ventrikel dari sinyal EKG [12]. Algoritma wavelet yang digunakan pada penelitian tersebut merupakan campuran antara algoritma Martinez dan Tompkinson.

Berdasarkan hasil penelitian yang telah dilakukan [13], JST MLP-BP menunjukkan hasil paling baik dibandingkan dengan model JST Generalized Feedforward Neural Network (GFFNN) dan Modular Neural Network (MNN). JST ini diaplikasikan pada klasifikasi normal dan abnormal pada sinyal EKG.

Pada penelitian ini didesain sistem klasifikasi aritmia berdasarkan fitur interval RR, lebar QRS, dan gradien gelom- bang R pada EKG menggunakan metode JST MLP-BP. Adapun output jaringan terdiri dari 4 jenis yaitu kondisi jantung normal, PVC, PAC, dan LBBB.

\section{METODE PENELITIAN}

Penelitian dilakukan dengan mengimplementasikan JST Multilayer Perceptron-Backpropagation (MLP-BP) kedalam perangkat lunak Matlab. Data yang digunakan sebagai bahan penelitian diambil dari basis data Massachusetts Institute of Technology Beth Israel Hospital (MIT-BIH). Pada penelitian ini digunakan data dari 14 pasien, yaitu pasien nomor 100, 109, 111, 115, 116, 119, 200, 202, 207, 209, 213, 221, 222, dan 228.

Rancangan sistem deteksi aritmia menggunakan metode JST ini ditunjukkan pada Gambar 2. Fitur-fitur yang digunakan dalam penelitian ini antara lain interval RR, lebar QRS serta gradient gelombang R. Fitur-fitur EKG ini kemudian dijadikan masukan pada sistem Jaringan Syaraf Tiruan (JST).

Sistem JST terdiri dari dua tahapan, yaitu tahap pelatihan dan tahap pengujian. Pada tahap pelatihan digunakan algoritma backpropagation. Data yang digunakan pada tahap ini sebanyak 6\% dari total keseluruhan data. Setelah tahap pelatihan selesai, selanjutnya menuju tahap pengujian. Pada tahap ini digunakan data sebanyak $94 \%$ dari total data keseluruhan. Tahap pengujian dilakukan pada masing-masing pasien serta gabungan data keseluruhan pasien (pasien nomor 100, 109, $111,115,116,119,200,202,207,209,213,221,222$, dan 228).

Agar dapat diketahui pengaruh jumlah fitur terhadap kinerja sistem deteksi maka dilakukan variasi jumlah fitur. Variasi yang dilakukan antara lain variasi dengan 3 buah fitur serta variasi dengan 2 buah fitur. Variasi dengan 2 buah fitur dilakukan dengan 3 macam cara, yaitu fitur gradien gelombang $\mathrm{R}$ dan interval RR, fitur lebar QRS dan gradien gelombang $\mathrm{R}$, serta lebar QRS dan interval RR.

\section{HASIL DAN PEMBAHASAN}

Telah dilakukan penelitian deteksi aritmia PVC, PAC dan LBBB dengan metode JST MLP-BP kelas jamak menggunakan fitur-fitur interval RR, lebar QRS serta gradien gelombang R. Penelitian dilakukan dengan mengimpelemntasikan metode tersebut pada perangkat lunak Matlab.

Total jumlah keseluruhan data yang digunakan yaitu sebanyak 32.297 denyut yang berasal dari 14 pasien. Rincian jumlah data setiap pasien ditunjukkan pada Tabel I.

Hasil ekstraksi fitur ditunjukkan pada Tabel II dan Tabel III. Hasil ekstraksi menunjukkan interval RR pada normal dan LBBB lebih lebar dibanding pada PVC dan PAC. Sementara lebar QRS pada PVC dan LBBB menunjukkan hasil yang lebih besar dibanding normal dan PAC. Meskipun nilai keduanya cenderung sama, namun PVC dan LBBB menunjukkan hasil berbeda pada hasil ekstraksi fitur interval RR maupun graiden gelombang R. Sama halnya dengan interval RR pada PVC dan PAC yang selisih nilainya kecil, namun pada lebar 


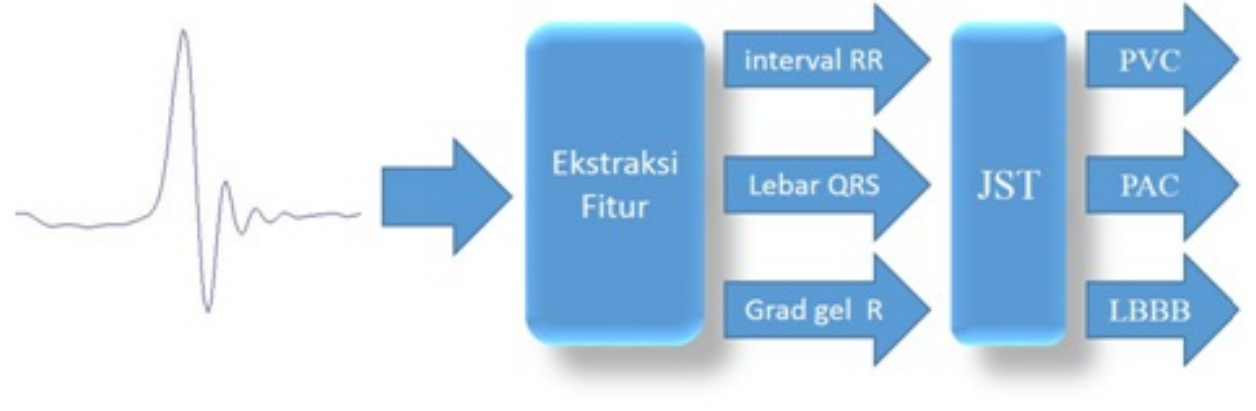

Gambar 2: Rancangan sistem deteksi aritmia.

TABEL I: Jumlah data normal dan aritmia masing-masing pasien.

\begin{tabular}{ccccc}
\hline \hline \multirow{2}{*}{$\begin{array}{c}\text { No } \\
\text { Pasien }\end{array}$} & Normal & \multicolumn{3}{c}{ A r i t m i a } \\
\cline { 3 - 5 } & & PVC & PAC & LBBB \\
\hline 100 & 2239 & - & 33 & - \\
109 & - & 38 & - & 2492 \\
111 & - & - & - & 2123 \\
115 & 1953 & - & - & - \\
116 & 2302 & 109 & - & - \\
119 & 1543 & 444 & - & - \\
200 & 1743 & 826 & 30 & - \\
202 & 2061 & 19 & 36 & - \\
207 & - & 105 & 107 & 1457 \\
209 & 2621 & - & 383 & - \\
213 & 2641 & 220 & 25 & - \\
221 & 2031 & 396 & - & - \\
222 & 2062 & - & 208 & - \\
228 & 1688 & 362 & - & - \\
\hline Total & 22884 & 2519 & 822 & 6072 \\
\hline \hline
\end{tabular}

TABEL II: Hasil ekstraksi fitur EKG untuk normal dan PVC.

\begin{tabular}{lcc}
\hline \hline Fitur & Normal & Aritmia PVC \\
\hline Interval RR & $0,769 \pm 0,195$ & $0.521 \pm 0,098$ \\
Interval QRS & $0,027 \pm 0,006$ & $0.051 \pm 0,014$ \\
Gradien Gelombang R & $0,131 \pm 0,029$ & $0.052 \pm 0,018$ \\
\hline \hline
\end{tabular}

QRS dan gradien gelombang $\mathrm{R}$ perbedaan nilainya cukup signifikan.

Interval RR pada denyut PVC lebih pendek dapat dikarenakan depolarisasi ventrikel dini menyebabkan gelombang $\mathrm{P}$ tidak muncul. Ketidakmunculan gelombang P mengakibatkan jarak antara puncak QRS denyut PVC dengan puncak QRS sebelumnya menjadi lebih sempit.

Pada denyut PAC, interval RR juga menunjukkan hasil yang

TABEL III: Hasil ekstraksi fitur EKG untuk PAC dan LBBB.

\begin{tabular}{lcc}
\hline \hline Fitur & \multicolumn{2}{c}{ Aritmia } \\
\cline { 2 - 3 } & PVC & LBBB \\
\hline Interval RR & $0.458 \pm 0.086$ & $0.805 \pm 0.104$ \\
Interval QRS & $0.033 \pm 0.016$ & $0.057 \pm 0.011$ \\
Gradien Gelombang R & $0.144 \pm 0.029$ & $0.089 \pm 0.022$ \\
\hline
\end{tabular}

TABEL IV: Hasil Pengujian dengan fitur interval RR, interval QRS, dan gradien gelombang R.

\begin{tabular}{|c|c|c|c|}
\hline $\begin{array}{l}\text { No Pasien } \\
\text { MIT-BIH }\end{array}$ & $\begin{array}{c}\text { Sensitivitas } \\
(\%)\end{array}$ & $\begin{array}{c}\text { Spesifiksi } \\
(\%)\end{array}$ & $\begin{array}{c}\text { Akurasi } \\
(\%)\end{array}$ \\
\hline 100 & 99,82 & 99,50 & 99,74 \\
\hline 109 & 97,60 & 94,70 & 96,90 \\
\hline 111 & 98,78 & 96,95 & 98,34 \\
\hline 115 & 93,38 & 92,83 & 93,26 \\
\hline 116 & 93,71 & 93,16 & 93,59 \\
\hline 119 & 93,71 & 93,16 & 93,59 \\
\hline 200 & 93,73 & 93,16 & 93,61 \\
\hline 202 & 93,73 & 93,16 & 93,61 \\
\hline 207 & 98,30 & 96,66 & 97,90 \\
\hline 209 & 93,41 & 92,83 & 93,28 \\
\hline 213 & 93,73 & 93,16 & 93,61 \\
\hline 221 & 93,71 & 93,16 & 93,59 \\
\hline 222 & 93,41 & 92,83 & 93,28 \\
\hline 228 & 93,71 & 93,16 & 93,59 \\
\hline $\begin{array}{l}\text { Semua } \\
\text { pasien }\end{array}$ & 94,63 & 93,94 & 94,49 \\
\hline
\end{tabular}

TABEL V: Hasil Pengujian dengan fitur interval QRS dan gradien gelombang R.

\begin{tabular}{|c|c|c|c|}
\hline $\begin{array}{l}\text { No Pasien } \\
\text { MIT-BIH }\end{array}$ & $\begin{array}{c}\text { Sensitivitas } \\
(\%)\end{array}$ & $\begin{array}{c}\text { Spesifiksi } \\
(\%)\end{array}$ & $\begin{array}{c}\text { Akurasi } \\
(\%)\end{array}$ \\
\hline 100 & 77,64 & 95,30 & 78,28 \\
\hline 109 & 88,82 & 75,73 & 86,02 \\
\hline 111 & 92,87 & 8,44 & 91,66 \\
\hline 115 & 84,05 & 69,42 & 81,57 \\
\hline 116 & 84,79 & 71,57 & 82,49 \\
\hline 119 & 84,79 & 71,57 & 82,49 \\
\hline 200 & 84,76 & 71,49 & 82,46 \\
\hline 202 & 84,76 & 71,49 & 82,46 \\
\hline 207 & 92,60 & 87,33 & 91,44 \\
\hline 209 & 84,02 & 69,37 & 81,55 \\
\hline 213 & 84,76 & 71,49 & 82,46 \\
\hline 221 & 84,79 & 71,57 & 82,49 \\
\hline 222 & 84,03 & 69,37 & 81,55 \\
\hline 228 & 84,79 & 71,57 & 82,49 \\
\hline $\begin{array}{l}\text { Semua } \\
\text { pasien }\end{array}$ & 86,18 & 75,07 & 84,15 \\
\hline
\end{tabular}


lebih kecil. Depolarisasi atrium pada PAC tidak terjadi sebagaimana mestinya, sehingga konfigurasi atau bentuk gelombang $\mathrm{P}$ berbeda dengan gelombang $\mathrm{P}$ sinus. Gelombang pada PAC sendiri terjadi sangat dini, sehingga gelombangnya terganggu sebelum gelombang sinus berikutnya [7]. Hal ini yang menyebabkan interval RR pada denyut PAC lebih pendek.

Hasil dari ekstraksi fitur kemudian menjadi masukan pada JST. JST yang digunakan adalah JST MLP-BP kelas jamak dengan algoritma pembelajaran backpropagation. Dikatakan kelas jamak karena output dari JST ini lebih dari satu neuron. Tahap pertama yang dilakukan ialah tahap pelatihan. Dari hasil pelatihan ini akan diperoleh bobot yang nantinya menjadi masukan pada tahap pengujian.

Variasi jumlah fitur dilakukan agar diketahui pengaruh jumlah fitur yang digunakan terhadap kinerja hasil pengujian. Variasi dilakukan dengan 3 macam fitur dan 2 macam fitur. Tahap pengujian untuk masing-masing variasi fitur dilakukan pada setiap pasien serta data gabungan keseluruhan pasien. Setelah diperoleh hasil pengujian, selanjutnya adalah menentukan kinerja dari JST yang digunakan.

Penentuan kinerja dilakukan dengan menggunakan 3 parameter, yaitu sensitivitas, spesifisitas serta akurasi. Sensitivitas merupakan jumlah denyut aritmia yang terdeteksi aritmia dibanding total denyut aritmia. Spesifisitas adalah jumlah jumlah denyut normal yang terdeteksi normal dibanding total denyut normal. Sedangkan akurasi merupakan perbandingan jumlah denyut aritmia dan normal yang terdeteksi benar dengan jumlah total denyut normal dan aritmia. Ketiga parameter ini ditunjukkan dalam bentuk prosentase. Perhitungan sensitivitas, spesifisitas serta akurasi berturut-turut ditunjukkan oleh persamaan

$$
\begin{aligned}
\text { Sensitivitas }(\%) & =\frac{T P}{T P+F N} \times 100 \\
\text { Spesifisitas(\%) } & =\frac{T N}{T N+F P} \times 100 \\
\text { Akurasi }(\%) & =\frac{T P+T N}{T P+T N+F P+F N} \times 100
\end{aligned}
$$

dengan TP (True Positive) adalah jumlah denyut aritmia yang terdeteksi benar, FP (False Positive) adalah jumlah denyut aritmia yang terdeteksi salah, FN (False Negative) adalah jumlah denyut normal yang terdeteksi salah, serta TN (True Negative) adalah jumlah denyut normal yang terdeteksi benar.

Hasil pengujian untuk tiga fitur maupun dua fitur ditunjukkan pada Tabel IV sampai Tabel VII. Dari hasil penelitian terlihat bahwa kinerja paling baik diperoleh dari hasil pengujian dengan tiga fitur yaitu fitur interval RR, lebar QRS dan gradien gelombang R. Pada hasil pengujian dengan tiga fitur diperoleh kinerja diatas $90 \%$ untuk keseluruhan pasien serta gabungan data seluruh pasien baik sensitivitas, spesifisitas maupun akurasi. Sedangkan hasil pengujian dengan fitur interval RR dan lebar QRS relatif kurang baik dibandingkan dengan hasil pengujian dengan variasi fitur lain. Gabungan dari ketiga fitur yang ada menunjukkan hasil yang paling optimal dibanding semua variasi fitur yang dilakukan.

\begin{tabular}{|c|c|c|c|}
\hline $\begin{array}{l}\text { No Pasien } \\
\text { MIT-BIH }\end{array}$ & $\begin{array}{c}\text { Sensitivitas } \\
(\%)\end{array}$ & $\begin{array}{c}\text { Spesifiksi } \\
(\%)\end{array}$ & $\begin{array}{c}\text { Akurasi } \\
(\%)\end{array}$ \\
\hline 100 & 96,83 & 98,37 & 97,18 \\
\hline 109 & 96,23 & 96,12 & 96,21 \\
\hline 111 & 92,73 & 87,28 & 91,52 \\
\hline 115 & 82,99 & 64,52 & 79,88 \\
\hline 116 & 84,05 & 68,04 & 81,27 \\
\hline 119 & 84,05 & 68,04 & 81,27 \\
\hline 200 & 84,21 & 68,58 & 81,48 \\
\hline 202 & 84,21 & 68,58 & 81,48 \\
\hline 207 & 93,96 & 90,07 & 93,08 \\
\hline 209 & 83,17 & 65,20 & 80,13 \\
\hline 213 & 84,21 & 68,58 & 81,48 \\
\hline 221 & 84,05 & 68,04 & 81,27 \\
\hline 222 & 83,17 & 65,20 & 80,14 \\
\hline 228 & 84.05 & 68.04 & 81,27 \\
\hline $\begin{array}{l}\text { Semua } \\
\text { pasien }\end{array}$ & 85,70 & 72,74 & 83,33 \\
\hline
\end{tabular}

TABEL VI: Hasil Pengujian dengan fitur interval RR dan gradien gelombang $\mathrm{R}$.

\begin{tabular}{|c|c|c|c|}
\hline $\begin{array}{l}\text { No Pasien } \\
\text { MIT-BIH }\end{array}$ & $\begin{array}{c}\text { Sensitivitas } \\
(\%)\end{array}$ & $\begin{array}{c}\text { Spesifiksi } \\
(\%)\end{array}$ & $\begin{array}{c}\text { Akurasi } \\
(\%)\end{array}$ \\
\hline 100 & 75,03 & 80,00 & 75,03 \\
\hline 109 & 97,47 & 96,50 & 97,24 \\
\hline 111 & 98,59 & 98,03 & 98,46 \\
\hline 115 & 74,21 & 0,00 & 71,93 \\
\hline 116 & 75,66 & 38,33 & 73,90 \\
\hline 119 & 75,66 & 38,33 & 73,90 \\
\hline 200 & 75,83 & 40,94 & 74,10 \\
\hline 202 & 75,83 & 40,94 & 74,10 \\
\hline 207 & 97,61 & 96,74 & 97,41 \\
\hline 209 & 74,40 & 7,73 & 72,18 \\
\hline 213 & 75,83 & 40,94 & 74,10 \\
\hline 221 & 75,66 & 38,33 & 73,90 \\
\hline 222 & 74,40 & 7,73 & 72,18 \\
\hline 228 & 75,66 & 38,33 & 73,90 \\
\hline $\begin{array}{l}\text { Semua } \\
\text { pasien }\end{array}$ & 79,30 & 71,00 & 78,58 \\
\hline
\end{tabular}

TABEL VII: Hasil Pengujian dengan fitur interval RR dan interval QRS.

\section{SIMPULAN}

Pada penelitian ini telah dilakukan deteksi aritmia Premature Ventricular Contraction (PVC), Premature Atrial Contraction (PAC), dan Left Bundle Branch Block (LBBB) dengan metode JST MLP-BP kelas jamak. Fitur-fitur EKG yang digunakan antara lain interval RR, lebar QRS serta gradien gelombang R. Variasi fitur yang dilakukan pada penelitian ini yaitu variasi dengan kombinasi fitur interval $R R$, lebar $Q R S$ dan gradien gelombang $\mathrm{R}$ (tiga fitur), kombinasi dua fitur yaitu gradien gelombang $\mathrm{R}$ dan lebar QRS, kombinasi fitur gradien gelombang $\mathrm{R}$ dan interval RR, serta kombinasi fitur lebar QRS dan interval RR. Rancangan program menunjukkan hasil terbaik dengan input JST tiga macam fitur. Hal ini dibuktikan dengan kinerja yang dihasilkan berupa sensitivitas, spesifisi- 
tas, serta akurasi cukup baik yaitu 94,63\%, 93,94\%, 94,49\%.

[1] WHO, The top 10 causes of death, http://www.who.int (2013), akses: 24 Maret 2014

[2] WHO, Projection of death rates: WORLD By cause, http://apps.who.int (2013), akses: 24 Maret 2014.

[3] Z. Abidin, Faktor Risiko Penyakit Jantung Koroner pada Pasien Rawat Inap Di Cardiovascular Care Unit (Cvcu) Cardiac Centre Rsup Dr. Wahidin Sudirohusodo Makassar periode Januari-Juli 2008, Disertasi, Fakultas Kedokteran Universitas Hasanuddin, 2012.

[4] D.D. Patil, et al., International Journal of Computer Science Issues (IJCSI), 9(1), 408-413 (2012).

[5] H. Milhorn, Electrocardiography for The Family Physician: The Essentials (Brown Walker Press, Florida, 2005).

[6] M.S. Thaler, The Only EKG Book You'll Ever Need Fifth Edition (Lippincott Williams \& Wilkins, 2007).

[7] Julian, R. Asti, N. Suciati, D. Herumurti, Klasifikasi Aritmia EKG Menggunangan Jaringan Saraf Tiruan dengan Fungsi Aktivasi Adaptif, Skripsi, Teknik Informatika, FTIF-ITS, Surabaya 2011.
[8] A.M. Vanage, R.H. Khade, and D.B. Shinde, International Journal of Computational Engineering \& Manegement (IJCEM), 15(4), 75-79 (2012).

[9] M. Fauziyah, T. Sriwidodo, Litasari, Pengembangan Jaringan Syaraf Tiruan Backpropagation untuk Klasifikasi Isyarat EKG, Prosiding SENTIA 2009, Maret 12-13, Politeknik Negeri Malang, 2009.

[10] R.S. Mane, et al., International Journal of Engineering Research and Applications (IJERA), 3(2), 327-332 (2013).

[11] E. Purwanti, Franky Chandra A. S., Pujianto, M.A. Bustomi, Jurnal Fisika Dan Aplikasinya, 9(2), 57-62 (2013).

[12] V. Ilankumaran, S. ThamaraiSelvi, International Journal of Computer Applications, 20(1), 11-18 (2011).

[13] S.M. Jadhav, S.L. Nalbalwar, A.A. Gathol, International Journal of Computer Applications, 44(15), 8-13 (2012).

[14] A. Iswanto, Perancangan Sistem Pendeteksi Aritmia Menggunakan Neural Network, Tugas Akhir, Jurusan Elektro, FTI-ITS, Surabaya, 2010 